\section{Science struck dumb}

\section{N. J. Mackintosh}

The $\boldsymbol{g}$ Factor: General Intelligence and its Implications. By Christopher Brand. Pp. 253. To have been published by Wiley*.

HERE is a novel way for a publisher to get free publicity for a newly published book: immediately withdraw it from publication, because you find some of the author's assertions repellent and have no wish to support his views by disseminating them.

I quote freely from a press release issued on 17 April by the president and chief executive of John Wiley, dissociating his company from Christopher Brand's The g Factor, due to be published the following day. This seems a singularly cack-handed attempt at censorship, and although the managers of Wiley may be congratulating themselves on the purity of their collective conscience, others may question their good sense, competence and integrity. How is it that they found out about the repellent nature of Brand's views only after they had printed and distributed copies of the book in which he expressed them? Do they not appreciate that attempts at suppression or censorship usually only enhance the reputation of otherwise rather undistinguished books (think of Lady Chatterley's Lover)?

\section{Spirited defence}

So what are Brand's abhorrent views? This is, of course, a book about IQ tests, and it will come as no surprise to learn that Brand thinks that IQ tests are a pretty good thing. The book is largely a spirited defence of four propositions. First, that IQ tests really do measure intelligence, and that the critics' arguments to the contrary are refuted by the claim that all attempts to find other measures of intelligence uncorrelated with IQ scores have failed. Second, that intelligence is a unitary process, largely reducible to speed of apprehension or intake of simple perceptual information. Third, that genetic differences are much more important than environmental differences as a cause of differences in IQ - both between individuals and between certain groups. And finally, that all this matters, because the intelligence measured by IQ tests is not just 'academic' intelligence, but something of much wider practical significance.

The defence of these propositions is liberally interspersed with even more spirited attacks on a variety of bogeymen, which include not only such expected

*For further details see this week's News section. targets as Stephen Jay Gould and Steven Rose, the massed battalions of the politically correct, and those who have sought to deny the possibility of estimating the heritability of IQ by insisting that genetic and environmental influences are inextricably intertwined and interact in ways too complex to understand, but also most other branches of psychology, including behaviourism, cognitive psychology and other less familiar brands labelled idealism and constructivism. And Brand is refreshingly willing to startle or shock his readers, as when he tells us of a particular idealistic psychologist from San Diego, with a sustained, scholarly interest in helping children with learning difficulties, whose great love is classical music and whose hero is Mahatma Gandhi. Who is this paragon of virtue? None other than Arthur Jensen.

Although this second aspect of the book will no doubt annoy some readers, there is little harm in that. It is the positions Brand defends that will raise more legitimate concern. There is, no doubt, much to be said for stating a position forthrightly and unambiguously. But that is not the same as going beyond the evidence. Not many readers will accept that the evidence justifies some of Brand's assertions. With little or no hesitation, he settles on 0.75 as an estimate of the broad heritability of IQ: this is at the upper limit of the plausible, and for some time now most behavioural geneticists have been content with a very rough estimate of 0.50 . Even more startling, if less likely to offend political sensibilities, is his confident assertion that IQ scores correlate 0.75 with performance on 'inspection time' tasks. This is the basis for Brand's claim that the nature of $g$, or general intelligence, has now been identified as speed of apprehension. I know of few other investigators who would claim that the correlation is greater than 0.50 , and my own reading of the evidence suggests that a figure of $0.35-0.45$ is much nearer the mark. Nor has Brand, or anyone else, ever established that inspection time owes its correlation with IQ scores to its correlation with $g$.

If you want to offend political sensibilities, there is no better way than to assert that in the United States blacks obtain lower average IQ scores than whites, and that this difference cannot be attributed to environmental differences. Although many would like to draw a discreet veil over this topic, there is no sensible way to deny the truth of the first of these propositions. But why should we believe that the difference is probably genetic in origin? Brand seeks to persuade the reader of this, and, I suspect, has succeeded in persuading himself, by the tactic of rubbishing so many other arguments advanced by the critics of IQ tests that one ends up persuaded that here too the politically correct critic has simply got it wrong. The tactic may be persuasive, but it should be resisted.

\section{Wishful thinking}

It is true that much criticism of IQ testing has been ignorant, tendentious and based on wishful thinking; contrary to the critics' arguments, IQ does have significant heritability, and IQ scores do predict, rather better than parental socioeconomic status, some reasonably important aspects of people's achievements. But it really does not follow that we can also dismiss the claim that black-white differences in average IQ may well be entirely environmental in origin. A moment's reflection should surely suggest how extraordinarily difficult it will be to rule out this possibility. The standard way to ascertain the role of genetic factors is to hold environmental differences constant. So to show that black-white differences in IQ are genetically caused, we should need to bring up black and white children in comparable environments. And how, in a racist society, are we going to do that?

Some people, perhaps including the New York managers of Wiley, will regard Brand as little better than a reactionary, racist ideologue. But that would not do justice to many of his views. In his last and longest chapter, he develops a strong argument for individual freedom of choice in education. Pointing out that the top 10 per cent of seven-anda-half-year-old children obtain higher IQ test scores than the bottom 10 per cent of fifteen-and-a-half-year-olds, he asks why we persist in segregating schoolchildren by chronological age rather than by mental age. Warming to his radical libertarian theme, he suggests that we should simply allow children to choose the intellectual level of their classes. Because it turns out that adults choose their friends, and spouses, by IQ (without of course knowing), he confidently predicts that schoolchildren would do so too. It is an idea at least worth injecting into debates on education.

N. J. Mackintosh is in the Department of Experimental Pyschology, University of Cambridge, Downing Street, Cambridge CB2 3EB, UK. 